\title{
Gap Junction Effects on Precision and Frequency of a Model Pacemaker Network
}

\author{
KATHERINE T. MOORTGAT, ${ }^{1,2}$ THEODORE H. BULLOCK, ${ }^{3,4}$ AND TERRENCE J. SEJNOWSKI ${ }^{1,5}$ \\ ${ }^{1}$ Howard Hughes Medical Institute, Computational Neurobiology Laboratory, The Salk Institute, La Jolla 92037; and \\ ${ }^{2}$ Department of Physics, ${ }^{3}$ Neurobiology Unit, Scripps Institution of Oceanography, ${ }^{4}$ Department of Neuroscience, and \\ ${ }^{5}$ Department of Biology, University of California, San Diego, La Jolla, California 92093
}

\begin{abstract}
Moortgat, Katherine T., Theodore H. Bullock, and Terrence J. Sejnowski. Gap junction effects on precision and frequency of a model pacemaker network. J. Neurophysiol. 83: 984-997, 2000. We investigated the precision of spike timing in a model of gap junctioncoupled oscillatory neurons. The model incorporated the known physiology, morphology, and connectivity of the weakly electric fish's high-frequency and extremely precise pacemaker nucleus (Pn). Two neuron classes, pacemaker and relay cells, were each modeled with two compartments containing Hodgkin-Huxley sodium and potassium currents. Isolated pacemaker cells fired periodically, due to a constant current injection; relay cells were silent but slightly depolarized at rest. When coupled by gap junctions to other neurons, a model neuron, like its biological correlate, spiked at frequencies and amplitudes that were largely independent of current injections. The phase distribution in the network was labile to intracellular current injections and to gap junction conductance changes. The model predicts a biologically plausible gap junction conductance of 4-5 nS (200-250 M $\Omega$ ). This results in a coupling coefficient of $\sim 0.02$, as observed in vitro. Network parameters were varied to test which could improve the temporal precision of oscillations. Increased gap junction conductances and larger numbers of cells (holding total junctional conductance per cell constant) both substantially reduced the coefficient of variation $(\mathrm{CV}=$ standard deviation/mean $)$ of relay cell spike times by $74-85 \%$ and more, and did so with lower gap junction conductance when cells were contacted axonically compared with somatically. Pacemaker cell CV was only reduced when the probability of contact was increased, and then only moderately: a fivefold increase in the probability of contact reduced $\mathrm{CV}$ by $35 \%$. We conclude that gap junctions facilitate synchronization, can reduce $\mathrm{CV}$, are most effective between axons, and that pacemaker cells must have low intrinsic CV to account for the low $\mathrm{CV}$ of cells in the biological network.
\end{abstract}

\section{IN T R O D U C T I O N}

Individual neurons from the pacemaker nucleus $(\mathrm{Pn})$ of certain weakly electric fish generate spikes with far greater temporal precision than any other neurons known (Moortgat et al. 1998, 2000). In addition, the precision in the weakly electric fish can change spontaneously and can be modulated by behavioral stimuli (Moortgat et al. 1998). It has been proposed that the high precision results from gap junction coupling among neurons in the Pn. In this study, we model the Pn neurons to test how their precision and its modulation are affected by network coupling, and what intrinsic cellular precision would be required. We constrain our compartmental

\footnotetext{
The costs of publication of this article were defrayed in part by the payment of page charges. The article must therefore be hereby marked "advertisement" in accordance with 18 U.S.C. Section 1734 solely to indicate this fact.
}

model with experimental data on Pn connectivity and neuron morphology (Dye and Heiligenberg 1987; Elekes and Szabo 1985) and responses to intracellular current injections (Dye 1991; Juranek and Metzner 1998; Moortgat et al. 2000).

Our study differs from previous research that has largely emphasized mechanisms for frequency locking and synchronization between cell units, often with the simplifying assumption of all-to-all coupling (Chow and Kopell 1999; Ernst et al. 1995; Hansel et al. 1995; Matthews and Strogatz 1990; Sherman and Rinzel 1991). Some modeling studies have focused explicitly on the temporal precision of oscillations and neural spiking (Enright 1980a,b; Shinbrot and Scarbrough 1999) but have concluded that thousands of cells are required for high precision. The Pn model presented here is based directly on a biological pacemaker network made up of only 150 rhythmically firing, sparsely coupled neurons whose behavioral importance is well understood.

The medullary Pn commands the timing of the weakly electric fish's electric organ discharge (EOD), which is part of the fish's active electrosensory system. The EOD is an electric dipole field which, in "wave-type" fish, oscillates at a frequency of $60-2,000 \mathrm{~Hz}$ with a coefficient of variation $(\mathrm{CV}=$ standard deviation/mean period) of $2 \times 10^{-4}$ corresponding to a standard deviation of the period (SD) as low as $0.14 \mu \mathrm{s}$ (Bullock 1970; Bullock et al. 1972; Moortgat et al. 1998). Both the high frequency and the low $\mathrm{CV}$ are maintained throughout the lifetime of a fish, but each can be modulated in behavioral contexts as well as pharmacologically (frequency: Dye 1987; Hagedorn and Heiligenberg 1985; Heiligenberg et al. 1981; Keller et al. 1991; CV: Moortgat et al. 1998). Weakly electric fish determine the locations of objects by evaluating relative phase and amplitude shifts at the electroreceptors that cover its body (Heiligenberg 1991; von der Emde et al. 1998). The low SD of the emitted electric field oscillations may be crucial to the fish's ability to make phase discriminations as small as 0.40 $\mu$ s (Carr et al. 1986).

When the Pn is cut away from the brain stem, its neurons continue to fire at the same frequency (Meyer 1984) and with the same precision (Moortgat et al. 2000) as in vivo. The adult Pn is comprised of 100-160 neurons, coupled solely via axosomatic, axoaxonic, and axodendritic gap junctions (Dye and Heiligenberg 1987; Elekes and Szabo 1985; Moortgat et al. 2000). The importance of different gap junction locations is not known and cannot readily be tested physiologically.

A Pn network model can thus be particularly tractable, with just 150 resistively coupled neurons. We show that while relay 
cell CV is substantially reduced by network coupling, the same does not hold for pacemaker cells. Taking this result in combination with the Pn physiology, we conclude that the high precision of pacemaker cells must largely result from singlecell rather than network properties. We also compare axosomatic to axoaxonic gap junction coupling and find the latter to have enhanced effects on precision and frequency.

Earlier versions of this work were included in a $\mathrm{PhD}$ thesis (Moortgat 1999).

\section{METHODS}

\section{Model neurons}

Because Pn neurons showed important voltage activity both above and below spike threshold (Moortgat et al. 2000), we used model neurons described by Hodgkin-Huxley equations (Hodgkin and Huxley 1952). The neuronal simulation package, NEURON (Hines 1993), was used to model two Pn neuron types: the pacemaker and relay cells, and their electrotonic interconnections as seen in the Pn of the weakly electric fish Apteronotus leptorhynchus. Each model cell had two compartments: one somatic and one axonic. Dendritic compartments were not included despite anatomic evidence for extensive relay cell dendrites (Dye 1991; Elekes and Szabo 1985) with gap junctions (Moortgat et al. 2000), because the dendrites are thought to be involved primarily in synaptic integration, being covered with chemical synaptic boutons from higher brain centers (Elekes and Szabo 1985). These higher centers modulate spike frequency but are not required for the continuous, phase-locked oscillations in the Pn.

The two model cell types are distinguished in part by their morphology, as seen in fixed and live Pn tissue (Dye 1991; Elekes and Szabo 1985; Moortgat et al. 2000). Model pacemaker cells have somata of 30 $\mu \mathrm{m}$ diam, and cylindrical axons of $8 \mu \mathrm{m}$ diam and $45 \mu \mathrm{m}$ length, whereas the larger model relay cells have somata of $65 \mu \mathrm{m}$ diam and cylindrical axons of $7 \mu \mathrm{m}$ diam and $40 \mu \mathrm{m}$ length. The length of the model cell's axon was chosen to roughly match the length of the biological cell's axon initial segment. We did not aim to model the full, branched axon or action potential propagation through it.

The model parameters used in each compartment for each cell type are listed in Table 1. Somatic leak currents were set to give input resistances of 20 and $5 \mathrm{M} \Omega$, respectively, for isolated pacemaker and relay cells, within the experimentally measured range for neurons in the intact Pn (Dye 1991; Juranek and Metzner 1998). The current and voltage dynamics of the two active conductances included in the model, sodium and potassium, were calculated using the HodgkinHuxley equations (Hodgkin and Huxley 1952)

$$
\begin{aligned}
-C \frac{\mathrm{d} V}{\mathrm{~d} t}=g_{\text {leak }}\left(V-E_{\text {leak }}\right)+ & \bar{g}_{\mathrm{Na}} m^{3} h(V- \\
& \left.E_{\mathrm{Na}}\right) \\
& +\bar{g}_{\mathrm{K}} n^{4}\left(V-E_{\mathrm{K}}\right)+I_{\text {inj }}+I_{\text {gap }}
\end{aligned}
$$

TABLE 1. Model parameters for pacemaker and relay cells and their two compartments

\begin{tabular}{llllll}
\hline \hline & \multicolumn{2}{c}{ Pacemaker } & & \multicolumn{2}{c}{ Relay } \\
\cline { 2 - 3 } \cline { 5 - 6 } & Soma & Axon & & Soma & Axon \\
\hline Diam & 30 & 8 & & 65 & 7 \\
$R_{\mathrm{a}}$ & 100 & 100 & & 100 & 500 \\
$g_{\text {leak }}$ & 0.0003 & 0.001 & & 0.001 & 0.001 \\
$g_{\mathrm{Na}}$ & 0.5 & 0.5 & & 0 & 0.5 \\
$g_{\mathrm{K}}$ & 0.02 & 0.02 & & 0 & 0.05 \\
\hline
\end{tabular}

The 2 cell types were modeled with the same differential equations, but with different parameter values for each compartment of each model cell type. Units are $\mu \mathrm{m}$ for diameter, $\Omega$-cm for axial resistance $R_{\mathrm{a}}$, and $\mathrm{S} / \mathrm{cm}^{2}$ for conductances.
TABLE 2. Forward and backward rate functions for ion channels

$$
\begin{gathered}
\alpha_{\mathrm{m}}=-0.1(V+40)\left[\exp \left(\frac{V+40}{10}\right)-1\right]^{-1} \\
\beta_{\mathrm{m}}=4 \exp \left(-\frac{V+65}{18}\right) \\
\alpha_{\mathrm{h}}=0.07 \exp \left(-\frac{V+65}{20}\right) \\
\beta_{\mathrm{h}}=\left[\exp \left(-\frac{V+35}{10}\right)+1\right]^{-1} \\
\alpha_{\mathrm{n}}=-0.01(V+55) \exp \left(\frac{V+55}{10}\right) \\
\beta_{\mathrm{n}}=0.125 \exp \left(-\frac{V+65}{80}\right)
\end{gathered}
$$

where $E_{\text {leak }}=-70, E_{\mathrm{Na}}=50, E_{\mathrm{K}}=-77.5 \mathrm{mV}$ are, respectively, the leak, sodium, and potassium reversal potentials; $I_{\mathrm{inj}}$ is the current injected; and $I_{\text {gap }}$ is the gap junction current entering the cell (see Model network). Table 2 lists the forward and backward rate constants, $\alpha$ and $\beta$, for $m, h$, and $n$. These were determined by fitting the model to the shapes of Pn cell action potentials, because detailed kinetic studies have not yet been conducted for these neurons. Calcium conductances are also important for the firing of Pn neurons (Dye 1991), but were not included in the model because little is known about their modes of action. The two model cell types contained the same active ionic currents and kinetics but differed in the balance of conductances to reflect physiological spike shapes and amplitudes. The potassium conductance had a maximum value $\bar{g}_{\mathrm{K}}$ chosen to reflect the spike width that was seen experimentally (see Fig. 3 of Moortgat et al. 2000, for example). Larger $\bar{g}_{\mathrm{K}}$ and $\bar{g}_{\mathrm{Na}}$ values narrowed the spike. The same maximum sodium conductance $\bar{g}_{\mathrm{Na}}$ was present in the axonic compartments of both cells and in the somatic compartment of the pacemaker cell type. The relay cell soma, on the other hand, had no active conductances. This lack of somatic conductance was suggested by experimental observations of low-amplitude spikes in the somata compared with those in the axon, an effect seen in both cell types (Dye and Heiligenberg 1987) but most pronounced in the relay cells (personal observation). The difference in spike amplitude between the model relay cell's soma and axon (Fig. 1, $B$ and $C$ ) was additionally enhanced by the axon's high axial resistance $R_{\mathrm{a}}$, which needed to be at least $\sim 250 \Omega$-cm to significantly decrease the somatic spike amplitude.

To give each pacemaker cell an "intrinsic" spiking frequency, at which it fired without being coupled to other cells, a constant current of $1 \mathrm{nA}$ was injected into each soma. The injected current took the place of a pacemaker current that would produce a pacemaker potential, as observed in the Pn pacemaker cells. Larger or smaller injected currents led to higher or lower spiking frequencies for these isolated cells. The 1 -nA value was chosen so the spike frequency $(\sim 612 \mathrm{~Hz})$ would fall in the biological range for the species studied (500-900 $\mathrm{Hz}$ ). The relay cells also received a constant current injection of 0.5 $\mathrm{nA}$, which depolarized them but did not bring them to spike threshold. Only with inputs from pacemaker cells did the relay cells spike at the pacemaker frequency. Larger current injections into relay cells further depolarized the membrane potential but did not cause repeated spiking; instead, the membrane potential resonated but did not repolarize fully, presumably because of a low $\mathrm{K}^{+}$channel density. In some simulations, the current injected was randomized between cells (giving each cell a different but fixed intrinsic frequency or interspike interval) and/or randomized over time (making the interspike interval slightly different for each interval). 

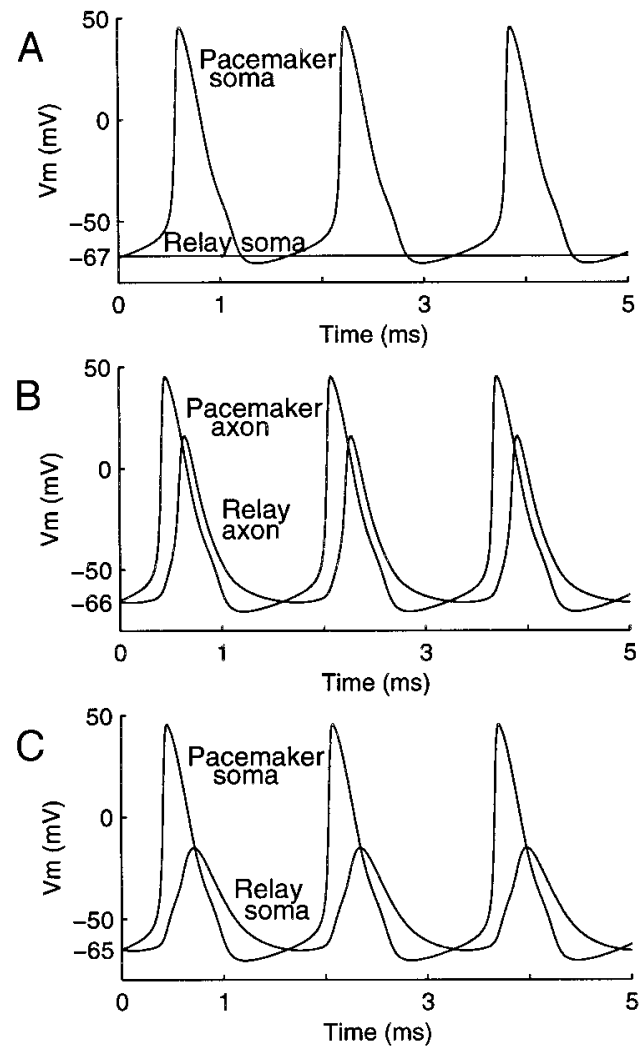

FIG. 1. Isolated model pacemaker cells fire periodically, whereas relay cells require network input to fire. $A$ : in an uncoupled network $\left(g_{\text {gap }}=0\right)$, a model pacemaker cell fired with a period of $\sim 612 \mathrm{~Hz}$, whereas a relay cell remained at a constant voltage not far from spike threshold. When the network was sufficiently strongly coupled (in this example, $g_{\text {gap }}=5 \mathrm{nS}$ ), the relay cell spiked periodically. The relay cell action potential was initiated in the axon $(B)$, causing a large voltage change with a small delay in the relay cell's passive soma $(C)$. Because the relay cell had active conductances only in the axon, the axonal waveform amplitude was significantly larger than that of its soma. Note that the pacemaker cell's membrane potential rose slowly before firing, whereas the relay cell fired rapidly from the baseline voltage.

\section{Model network}

Model networks contained a 4:1 ratio of pacemaker and relay cells. The total number of neurons in the model was varied from 50 to 200 . Unless otherwise specified, the model contained 150 neurons, with 120 pacemaker and 30 relay cells. Model neurons were coupled by resistive (gap junction-like) connections, such that the current $I_{\text {gap }}$ between connected cells was proportional to the difference in the cells' membrane potentials, $v$ and $v_{\text {pre }}: I_{\text {gap }}=g_{\text {gap }} \times\left(v-v_{\text {pre }}\right)$, where $g_{\text {gap }}$ is the gap junction conductance. Each pacemaker axon contacted $35 \%$ of relay cells and $7 \%$ of other pacemaker cells, chosen randomly (Fig. 2A). For a network of 150 neurons, each pacemaker cell contacted an average of 18.5 cells total. This resulted in a mean of 42 and
8 contacts, respectively, received by each relay and pacemaker cell (Fig. 2B).

The gap junction contacts were rectified, with current flowing from a pacemaker cell axon into a contacted cell's soma or axon. That is, gap junction connections were axosomatic or axoaxonic, depending on the simulation, and only passed current when the contacted cell's voltage was lower than that of the cell contacting it. It is not known whether gap junctions in the electric fish's Pn are rectified. The biological gap junctions, however, occur at long distances along multiple axon branches from the axon initial segment, and the rectified gap junction would seem to best model this. An unrectified antidromic subthreshold signal would decrement to insignificance over the long axonal distance. Gap junction conductance varied between simulations from 0.5 to 10 nanosiemens $(\mathrm{nS})$ per contact, equivalent to a resistance of $100-2000 \mathrm{M} \Omega$.

Simulations of the full network, using Euler integration with a time step of $1 \mu \mathrm{s}$, took $\sim 100 \mathrm{~s}$ real time per ms of simulated time (Dec Alpha server 2100/300). The first $10 \mathrm{~ms}$ of each simulation was considered to be settling time and was discarded from our analysis. Voltage measurements were made at the soma, unless otherwise indicated.

\section{RES ULT S}

We tested how well the network model yielded the electrophysiological results (Moortgat et al. 2000) and used the model to make predictions for future physiological studies. The general strategy was to explore the network properties with the given parameter values, not to search for the best parameter values for each simulation.

\section{Spike shape and amplitude depend on cell type}

Isolated model pacemaker cells fired periodically with a mean intrinsic frequency of $612.5 \mathrm{~Hz}$. Relay cells had no spontaneous rhythm, but had a resting membrane potential close to spike threshold (Fig. 1A). When the pacemaker and relay cells were coupled together with axosomatic gap junctions of $5 \mathrm{nS}$ conductance, they caused a voltage deflection in the passive relay cell soma that reached the axon with sufficient amplitude to cause the axon to spike (Fig. 1B). The relay cell action potential rose abruptly from the minimum membrane potential, whereas the pacemaker cell showed a prolonged "pacemaker potential" before the spike onset. Another difference between the cell types was the brief "shoulder" in the relay somatic waveform (Fig. $1 C$ ), which occurred at about one-half the oscillation amplitude in the form of a decrease in the voltage slope. Adding small somatic conductances, at least up to $10 \%$ of axonic conductances, did not remove the shoulder, but did increase the amplitude of the somatic voltage oscillations from 50 to $85 \mathrm{mV}$. However, model relay cells that
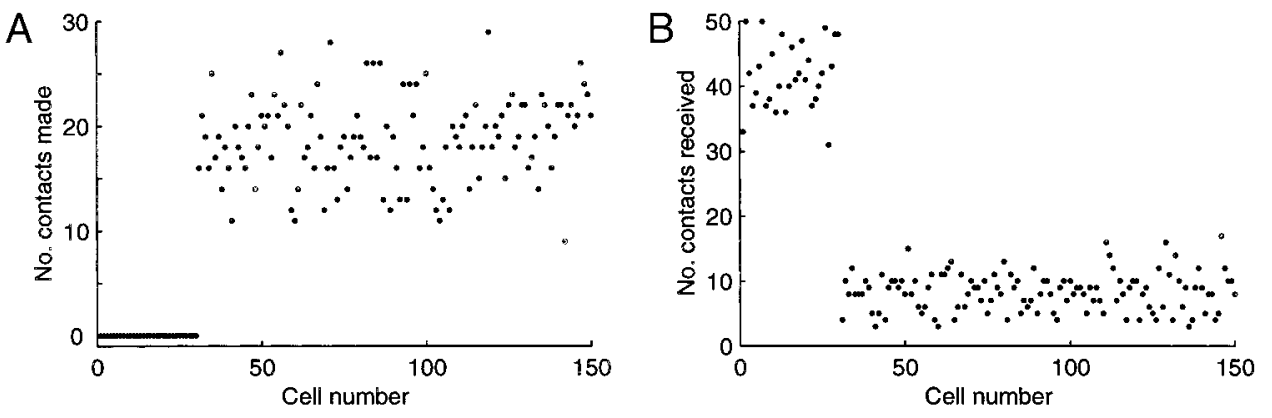

FIG. 2. Number of contacts between each cell pair was chosen from a random distribution that depends on the cell types. $A$ : each pacemaker cell axon (cell numbers 31-150) made an average of 18.5 total contacts to other cells. Relay cell axons (cell numbers 1-30) did not contact any other cell in the network. $B$ : relay and pacemaker cells, respectively, received an average of 42 and 8 contacts, reflecting the convergence of pacemaker axons onto relay cells. 


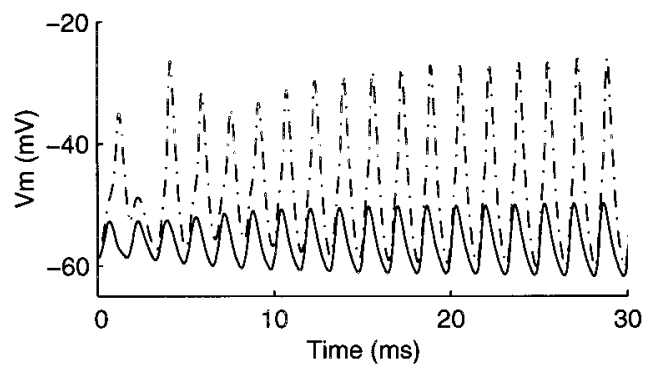

FIG. 3. Amplitude of the voltage oscillations in relay cells increased during the first $30 \mathrm{~ms}$ of simulation. In a passive relay cell (solid line) the gap junction input caused only a 5-mV voltage oscillation, but this amplitude grew to a constant of $13 \mathrm{mV}$ over 15 oscillations. When another simultaneously simulated relay cell (dashed line) had all its normal active conductances, the oscillation amplitude increased similarly. These amplitude increases occurred concurrently with a broadening in the phase distribution among model cells, which were initiated $(0 \mathrm{~ms}$ on graph) in the simulation with zero phase lag. This simulation was run with axosomatic gap junctions of particularly low conductance $\left(g_{\text {gap }}=1 \mathrm{nS}\right)$ to increase the time constant of the amplitude increases.

had a more depolarized intrinsic membrane potential, did not show the shoulder. Also, when axosomatic gap junctions were replaced with axoaxonic ones, the shoulder disappeared. Thus the shoulder in the passive somatic waveform of these cells appeared to result from the delay between somatic gap junction input and the antidromic axonal spike arriving at the soma.

\section{Nonzero phase lag between cells in the model network}

The model relay cell in Fig. $1, B$ and $C$, fires with a phase delay after the pacemaker cell. We calculated the phase lag,
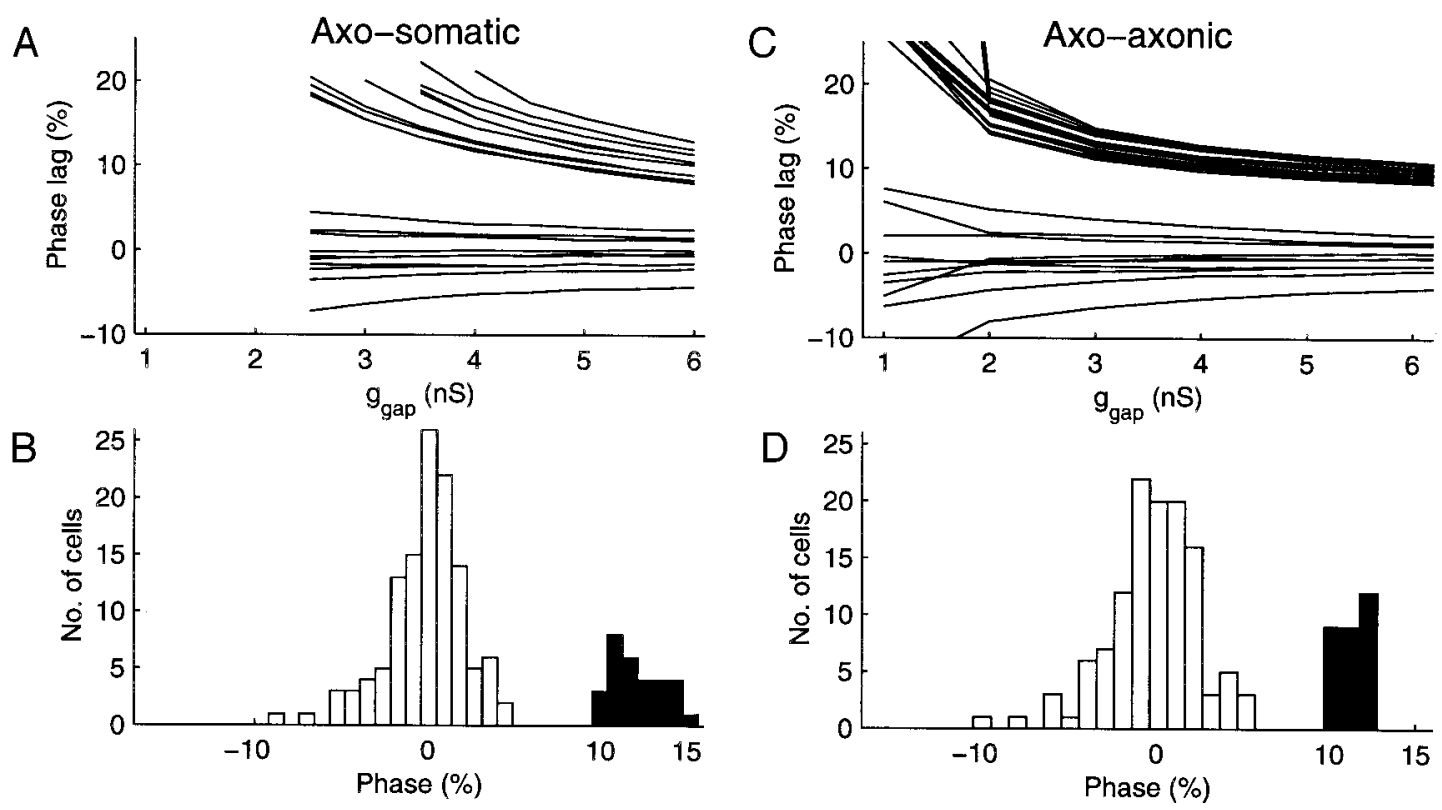

FIG. 4. Phase lag between and within cell types decreases with increasing $g_{\text {gap }} \cdot A$ : a representative subset of the cells in a model network connected by axosomatic gap junctions showed decreased phase lag with increased gap junction conductance $\left(g_{\text {gap }}\right)$. Each line follows the phase lag of an individual cell relative to the mean pacemaker cell spike time, as $g_{\text {gap }}$ increased. Larger $g_{\text {gap }}$ values recruited more relay cells (the top lines, with greatest phase lag) into the network oscillation. By $4 \mathrm{nS}$, all relay cells fired with the network period. $B$ : the phase distribution for all cells in the network with axosomatic coupling is plotted for $g_{\text {gap }}=5 \mathrm{nS}$, a value that leads to a phase delay between the average pacemaker cell (shown in white) to a relay cell (shown in black) of 9.5-15.7\% of the cycle period. $C$ : in a network coupled with axoaxonic gap junctions, the relay cells were all recruited with $\sim 1 / 2$ the $g_{\text {gap }}$ required for axosomatic coupling. $D$ : the phase distribution for all cells in the network with axoaxonic coupling is plotted for $g_{\text {gap }}=4 \mathrm{nS}$, resulting in a pacemaker-to-relay cell delay of $\sim 9.7-12.8 \%$ of the cycle period. The subdistribution of relay cells was more sharply peaked in the network with axoaxonic rather than axosomatic coupling. 
rhythm (Fig. 4B). If the relay cells received an "intrinsic" depolarization that was larger than specified in METHODS, then a smaller $g_{\text {gap }}$ was required to recruit all relay cells with a $10-15 \%$ phase lag.

\section{Phase distribution: axoaxonic versus axosomatic coupling}

The phase lag between model pacemaker and relay cells best matched the biologically observed distribution when axosomatic gap junctions had 5-nS conductance (equivalent to a resistance of $200 \mathrm{M} \Omega$ ). However, networks coupled with axoaxonic coupling required only $4 \mathrm{nS}(250 \mathrm{M} \Omega$ resistance) gap junction conductance to attain a similar phase lag (mean of $11.4 \%)$. Axoaxonic coupling also recruited all relay cells into the network oscillations at a lower conductance (Fig. 4C) than did axosomatic coupling (Fig. 4A). In addition, axoaxonic coupling of 4-nS conductance narrowed the phase distribution within the relay cells $(9.7-12.8 \%$, Fig. $4 D)$ relative to axosomatic coupling of $5 \mathrm{nS}(9.5-15.7 \%$, Fig. $4 B)$. Further network simulations use the value of $g_{\text {gap }}$ that gave the best match with biological phase distributions; namely, $5 \mathrm{nS}$ for axosomatic or $4 \mathrm{nS}$ for axoaxonic network coupling. Thus an average relay cell in a network with axosomatic coupling will have a total gap junction conductance of $210 \mathrm{nS}$ (mean of 42 contacts: see METHODS), whereas a pacemaker cell will have on average 40-nS total gap junction conductance. These values are relatively small compared with the conductance between a relay cell's axon and soma (750 nS) or a pacemaker cell's axon and soma $(4,500 \mathrm{nS})$. The increased membrane conductance through gap junctions leads to input resistances of 13 and 2.5 $\mathrm{M} \Omega$, respectively, for pacemaker and relay cells in a network with axosomatic gap junctions of $5 \mathrm{nS}$.

\section{Coupling coefficients between coupled cells are small}

We measured the coupling coefficients between axosomatically coupled pacemaker and relay cells for the gap junction conductance determined above. The coupling coefficient is the ratio of the passive voltage deflection in one cell $\left(\Delta V_{2}\right)$ in response to a voltage change $\left(\Delta V_{1}\right)$ in the coupled (presynaptic) cell $\left(\Delta V_{2} / \Delta V_{1}\right)$. This measure could not be directly applied to the model cells because they spiked rhythmically with short interspike intervals such that their voltages continuously oscillated. We measured the coupling coefficient as the ratio of the minimum somatic voltage during the spike's repolarization phase (trough) before and during a constant current injection in the presynaptic cell's soma. The minimum voltage in one model pacemaker cell shifted with injected current. We expected a substantial shift in a directly coupled cell's minimum voltage, but found only a small one. The coupling coefficients were $\sim 0.02$ and 0.025 for two different pacemaker cells contacting a single relay cell. Even simultaneously injecting current into two pacemaker cells that were coupled to a relay cell caused the latter's minimum voltage to shift by only $1.5 \mathrm{mV}$, whereas that of the directly injected pacemaker cells changed by 14 and $42 \mathrm{mV}$, respectively. Similarly small coupling coefficients are consistent with in vitro results (Moortgat et al. 2000) and were observed even when the model relay cell's active conductances were removed, making the cell entirely passive. Thus the currents from each individual gap junction make only small voltage deflections in the postsynaptic cell.
However, the sum of all gap junction inputs to a cell can be substantial, as shown below.

\section{Axosomatically coupled cells: responses to intracellular current injection}

Pacemaker and relay cells, coupled by axosomatic gap junctions of 5-nS conductance, were injected somatically with step currents of various amplitudes. Moderate somatic current injection ( -4 to $+2 \mathrm{nA})$ into one model relay cell linearly altered the phase lag of the injected cell's spikes relative to those of a model pacemaker cell (Fig. 5A) and changed the spike amplitude from 69 to $50 \mathrm{mV}$ (Fig. $5 B$ ). Currents of up to $\pm 2 \mathrm{nA}$ varied the peak voltage of the spike by only $2.5 \mathrm{mV}$ (Fig. 5C). Large depolarizing currents $(>4 \mathrm{nA})$ reduced the slope with which the phase lag changed as current increased, whereas large hyperpolarizing currents $(-4$ to $-10 \mathrm{nA})$ increased the slope. For these large currents, the amplitude of relay cell oscillations continued to decrease, though only slightly, with more positive current. Hyperpolarizing currents larger than $-13 \mathrm{nA}$ caused the relay cell's oscillation amplitude to drop to $48 \mathrm{mV}$, where it remained, even with further increased hyperpolarizing current. These massive hyperpolarizing currents also reduced the peak spike voltage and caused it to decrease more rapidly with more negative current. The current amplitude required for each of these effects varied from cell to cell, with a relay cell reaching a constant amplitude oscillation with as little as $-7 \mathrm{nA}$ or as much as $-14 \mathrm{nA}$. The larger currents were required for relay cells that received more gap junction contacts. Compared with relay cells, pacemaker cells had qualitatively similar but more sensitive responses to current injections. For example, a pacemaker cell's oscillation amplitude reached a fixed value with only $-2.5 \mathrm{nA}$. None of the intracellular current injections perturbed the frequency of the injected cell's voltage oscillations away from the model network frequency, just as observed in vitro (Moortgat et al. 2000).

\section{Axoaxonically coupled cells: responses to current injection}

In the same network, now coupled with axoaxonic gap junctions of 4 ns conductance, the phase lag of the same relay cell was more resistant to the somatic step current injections (Fig. 5D). That is, the phase lag during injection of $-10 \mathrm{nA}$ was only $17.8 \%$, compared with $20.3 \%$ in the axosomatically coupled network. Also, currents of 4-10 nA did not alter the phase lag from $8 \%$ in the axoaxonically coupled network. The relay cell in this network more than halved its oscillation amplitude (from 68 to $31 \mathrm{mV}$; Fig. 5E), and dropped its peak voltage from -39 to $-96 \mathrm{mV}$ (Fig. $5 F$ ) with a shift in injected current from -10 to $-14 \mathrm{nA}$. Despite these differences between the relay cell in the two network configurations, the qualitative responses were similar.

\section{Passive and active membrane voltage oscillations}

The reason for the abrupt changes in the relay cell's current response became clear by comparing the cell's normal (Fig. 5, $E$ and $F, \bigcirc$ ) to its passive response (Fig. 5, $E$ and $F, \triangle$ ). The relay cell's response to currents of $-14 \mathrm{nA}$ or more negative, and of $4 \mathrm{nA}$ or more positive, was predominantly passive. That is, the $\mathrm{Na}^{+}$and $\mathrm{K}^{+}$conductances were not activated. During these current injections, the somatic membrane voltage contin- 
Axo-somatic
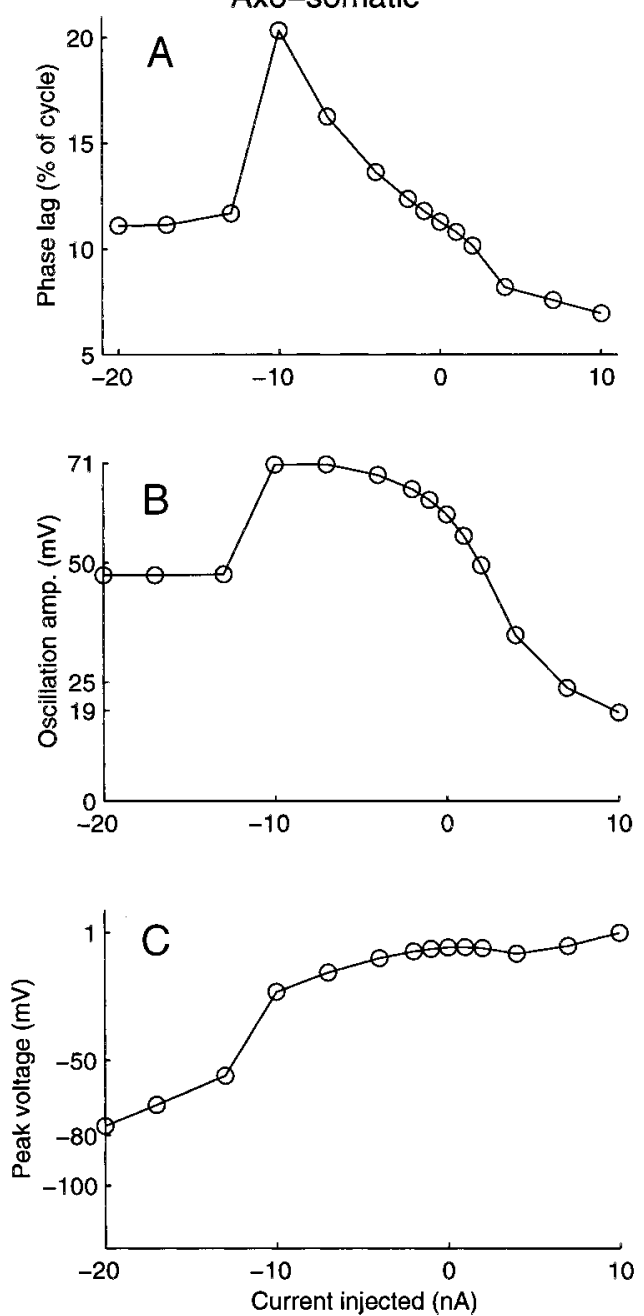

Axo-axonic
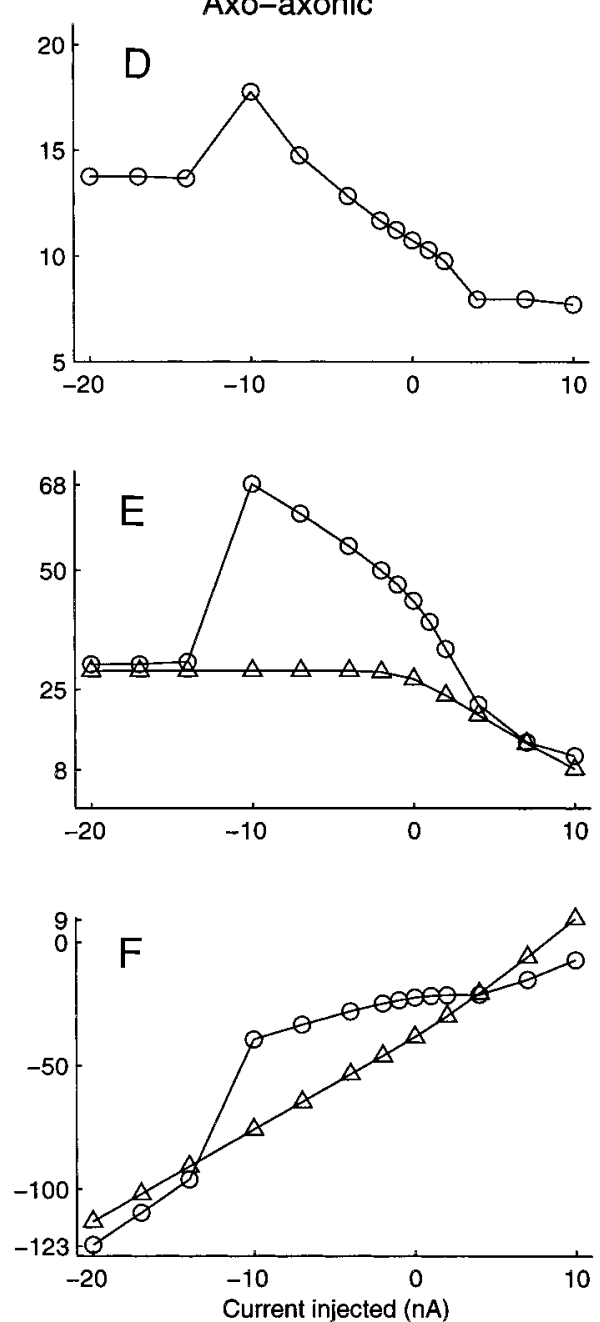

FIG. 5. Model relay cell responds with 2 voltage components to somatic current injection. $A-C$ : results for axosomatic network coupling. A: phase lag (measured as a percent of the cycle period) between the relay cell and one reference pacemaker cell increased with hyperpolarizing current, and decreased with depolarizing current injected into the relay cell soma. This pair of cells was not directly coupled. $B$ : the oscillation amplitude in same model relay cell increased with hyperpolarizing currents up to $-10 \mathrm{nA}$, and then dropped. Larger hyperpolarizing currents led to much slower amplitude increases. Depolarizing current decreased the oscillation amplitude, first rapidly, then, with $\sim 4 \mathrm{nA}$ and greater depolarizing current, more slowly. $C$ : the peak somatic voltage of the relay cell during an oscillation increased with more positive current injections. Only a small range of current injections $( \pm 2$ $\mathrm{nA}$ ) yielded relatively fixed-peak oscillations $( \pm 2.5 \mathrm{mV}) . D-F$ : results for axoaxonic network coupling. $D$ : the phase lag of the same model relay cell relative to the same reference pacemaker cell as in $(A)$ responded to current with qualitative but not quantitative similarity to $A$ : for a given current injection, the phase lag for axoaxonic coupling was less than for axosomatic coupling. E: the oscillation amplitude $(O)$ had 2 components. One component is the passive cell response $(\triangle$, all active conductances removed); the other the active response. When the current injection was too high, active conductances shut down, but the membrane voltage continued to oscillate by $\sim 30 \mathrm{mV}$, entirely due to the passive response to gap junction inputs. The amplitude ranged more widely with axoaxonic than with axosomatic $(B)$ coupling. $F$ : the peak voltage of the oscillations increased monotonically, but only step-wise linearly with more positive current injection. The passive cell changed its peak voltage linearly, matching the active cell peak voltage when current injections made spiking impossible. The current amplitudes tested are $-20,-17,-14,-10,-7,-4$, $-2,-1,0,1,2,4,7$, and $10 \mathrm{nA}$.

ued to oscillate; for $-14 \mathrm{nA}$, oscillation amplitudes were 48 $\mathrm{mV}$ for axosomatic and $31 \mathrm{mV}$ for axoaxonic coupling, roughly the same amplitudes seen in the passive cell at rest $\left(I_{\text {inj }}=0\right)$. Thus large membrane oscillations in the highly hyperpolarized or depolarized cell were due entirely to gap junction currents. The active membrane processes of this relay cell shut down between -10 and $-14 \mathrm{nA}$, causing the transition from larger amplitude action potentials to smaller amplitude (but still sizeable) voltage oscillations caused by gap junction inputs. Apparently the axoaxonic gap junction inputs failed to bring the cell to spike threshold when the cell received massive hyperpolarizing current, and only brought about passive subthreshold membrane oscillations. The amplitudes of the passive oscillations were significantly less voltage dependent than the active processes.

To understand the difference in the relay cell response between the two types of network coupling, consider the relative location of the recorded voltage signal and the gap junctions. The voltage was recorded in the soma. Gap junction inputs at the relay soma caused larger amplitude somatic mem- 


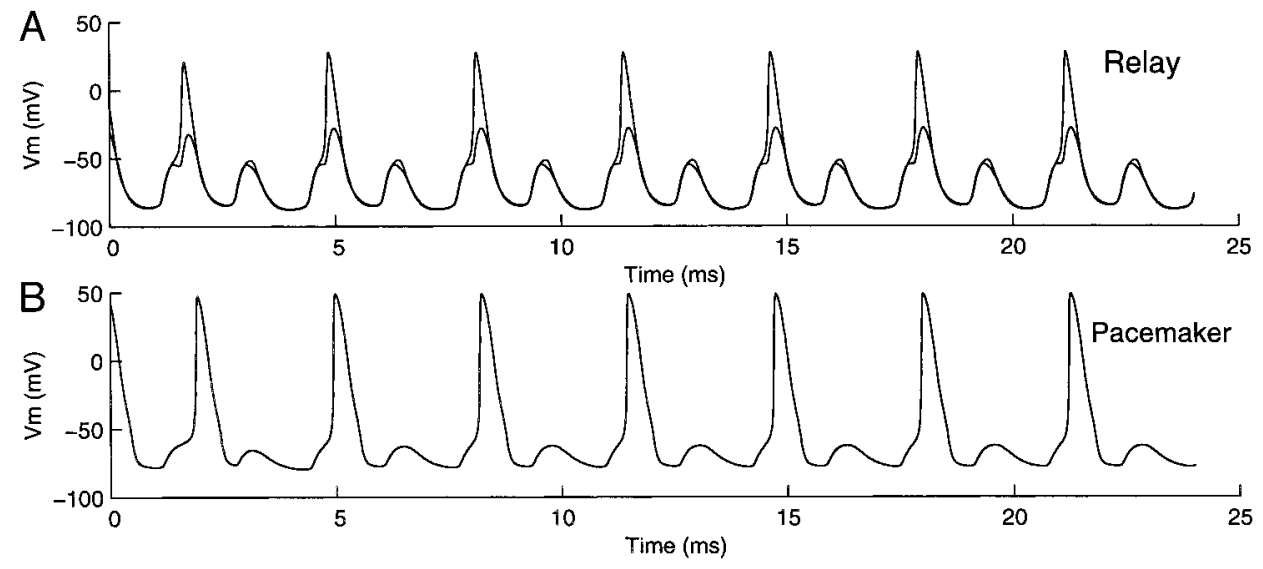

FIG. 6. Hyperpolarizing current injections over a narrow range causes both model cell types to fire in 1:2 locking with the network oscillations. A: during somatic injection of $-12.2 \mathrm{nA}$, a relay cell soma (smaller amplitude) and axon (larger amplitude) fired only once every 2 cycles of the model network; during the other network cycle, the membrane potential predominantly reflected the passive cell response to gap junction input. Some active process during the skipped spike is indicated by the changing minimum membrane potential, which is more negative after a skipped spike than after a full spike. $B$ : with injection of $-0.58 \mathrm{nA}$, this pacemaker cell failed to spike every other network cycle. The minimum membrane potential was constant. brane oscillations than inputs at the axon because the signal was not dampened by the axon's high axial resistance. Hence, the passive somatic oscillation amplitude was larger for axosomatic than axoaxonic coupling. Similarly, the peak somatic voltage of the passive oscillation was greatest when the currents driving the oscillation arrived directly at the soma, rather than resistively through the axon (compare Fig. 5, $C$ and $F$ ).

\section{Passive oscillations can alternate with spikes within a narrow range of hyperpolarizing current}

In the narrow transition between the full amplitude spikes and passive oscillations (Fig. 5), model pacemaker and relay cells could spike in integral ratios of the network frequency. The most common and stable pattern was one spike for every two cycles of the model Pn network, in a 1:2 ratio (as shown in Fig. 6, $A$ and $B$ ). Lower ratios, including 1:3, 1:4, and 1:5, were also observed in both pacemaker and relay cells. In some cases, lower ratios settled into a 1:2 ratio with continued (beyond $\sim 20 \mathrm{~ms}$ ) current injection. Other cases of low spiking ratios were sustained indefinitely, with each oscillation within the pattern having a lower amplitude until a minimum was reached. After the minimum amplitude oscillation, the next oscillation had the full spike amplitude. Only a narrow range of currents, typically within $\pm 0.5 \mathrm{nA}$ for a relay cell and $\pm 0.1 \mathrm{nA}$ for a pacemaker cell, caused the cells to alternate between passive oscillations and spikes in any ratio.

To confirm that the lowest amplitude oscillations were indeed the cell's passive response to gap junction input, we removed the cell's active conductances. The membrane potential during the low-amplitude oscillation had the same amplitude and peak voltage when the cell's active properties were removed. Thus the low-amplitude membrane oscillations were truly "skipped spikes": the cell's passive response to gap junction input, and had no active membrane component.

\section{Differences in peak voltage alternations between relay and pacemaker cells}

Pacemaker and relay model cell waveforms differed somewhat during these hyperpolarizing current injections. These differences mirrored in vitro observations (see Moortgat et al. 2000, Figs. 5 and 6 and section entitled Skipped spikes during massive current injection). First, the pacemaker cell's passive membrane oscillation had a significantly smaller amplitude than the relay cell's. This difference reflected the larger num- ber of gap junction contacts onto the relay cell than onto the pacemaker cell, and hence the smaller gap junction currents. Second, the model pacemaker and relay cell waveforms differed in the minimum membrane potential reached during the repolarization phase after active spikes and passive oscillations. Specifically, the relay cell's minimum membrane potential was more hyperpolarized after a passive membrane oscillation than after an action potential. In contrast, pacemaker cells usually had the same minimum voltage after a spike as after a passive oscillation. In a few model pacemaker cells, the minimum membrane potential was more hyperpolarized after a full spike than after a passive oscillation, the opposite of relay cells. The cause for the differences between pacemaker and relay cell minimum voltages is not known, but is consistent with biological observations.

Similar alternations between passive oscillations and active action potentials were seen in a network with axoaxonic coupling. In this case, the relay cells required more hyperpolarizing current $(-16 \mathrm{nA}$ for a cell that required $-12 \mathrm{nA}$ with axosomatic coupling) to spike in a 1:2 locking with the network oscillations. The range of hyperpolarizing currents that caused the alternations was even narrower in networks with axoaxonic coupling than in those with axosomatic coupling.

\section{How should noise be added to the deterministic model?}

We further tested which network parameters had the strongest effect on the spike timing precision, as measured by the coefficient of variation $(\mathrm{CV}=$ standard deviation/mean) of each cell's interspike intervals. First, the time step of the simulation was set to $\Delta t=1 \mu \mathrm{s}$ to allow detection of CVs $>3 \times 10^{-4}$, within the range observed physiologically (Moortgat et al. 2000). Then, a time-varying Gaussian noise (updated every time step for each cell) was added to the deterministic model. Two sites for the noise were considered: the conductance of the leak current and the constant current that sets each cell's intrinsic frequency. The former proved inappropriate because of its limited dynamic range. That is, the standard deviation had to be approximately equal to the mean leak conductance to produce a sufficiently high $\mathrm{CV}$. In addition, adding noise to the leak conductance implied a voltage-dependent noise, an unnecessary complication. 
A

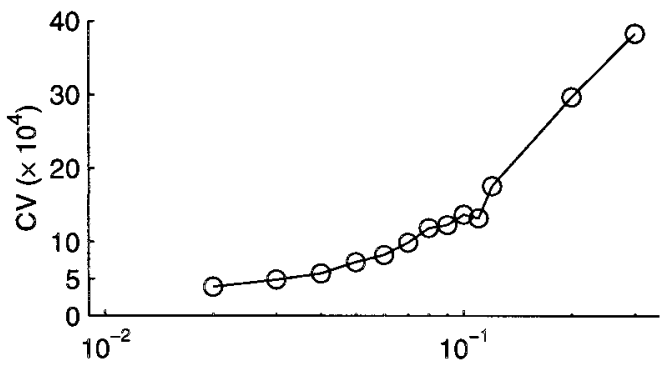

B

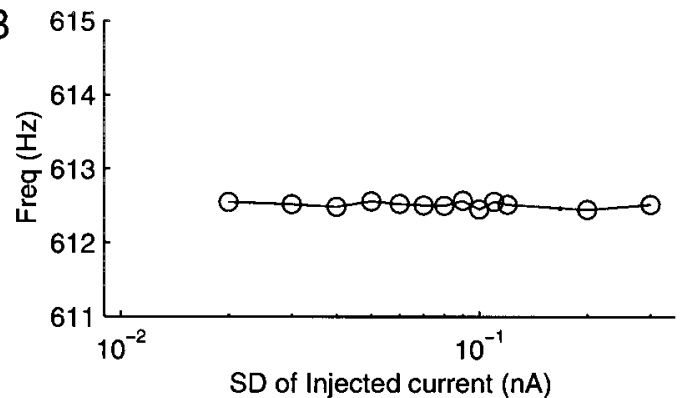

FIG. 7. For an isolated model pacemaker cell, the coefficient of variation (CV) but not the frequency of spiking increased with larger SD of fluctuations in the injected current. A: isolated pacemaker cell was injected with a Gaussian noise current of constant mean (1 nA) and a range of SDs (abscissa). Increasing the SD of the injected current increased the CV of spike times. A SD of 0.1 and $0.2 \mathrm{nA}$, respectively, yields a spike timing CV of $\sim 14 \times 10^{-4}$ and $30 \times 10^{-4}$ for the single cell. $B$ : spiking frequency of the isolated pacemaker cell remained constant with increased SD of the injected current

\section{Time-varying current noise increases cell $\mathrm{CV}$}

Time-varying Gaussian noise was added to the current that sets each cell's intrinsic frequency. An isolated pacemaker cell, i.e., a single cell outside the network, was injected with this noise current. A range of standard deviations of the noise current was explored, and the resulting $\mathrm{CV}$ of interspike intervals was measured (Fig. 7A). The CV was limited by $\Delta t=1 \mu \mathrm{s}$ for noise currents with SD less than $\sim 0.02 \mathrm{nA}$, but increased with larger SDs of the injected current. For an isolated pacemaker cell to spike with $\mathrm{CV}=10^{-3}$ or $3 \times 10^{-3}$, the injected noise had, respectively, $\mathrm{SD}=0.1$ and $0.2 \mathrm{nA}$.

\section{Specification of the noise used in subsequent simulations}

In the following simulations, pacemaker cells that had CVs of $\sim 3 \times 10^{-3}$, due to cell-dependent, time-varying injected current noise of SD $=0.2 \mathrm{nA}$, were coupled to relay cells injected with current of the same SD. These neurons had independent noise that was updated every time step, and were coupled with axosomatic or axoaxonic gap junctions.

\section{Increased gap junction conductance: effects on $\mathrm{CV}$ and frequency}

We investigated the effects of gap junction conductance on the spike timing precision of relay and pacemaker cells. A network of 150 neurons (120 pacemaker and 30 relay cells, each with independent noise of the same $\mathrm{SD}=0.2 \mathrm{nA}$ ) was coupled with axosomatic gap junctions. Gap junction conductances ( $g_{\text {gap }}$ ) of $\leq 1 \mathrm{nS}$ failed to drive relay cells to the firing frequency of the pacemaker cells $(612.5 \mathrm{~Hz})$. Some relay cells fired every other pacemaker cycle in the same pattern described above for the hyperpolarized cell in a network of normal $g_{\text {gap }}$ $(5 \mathrm{nS})$. For $g_{\text {gap }}=1.5 \mathrm{nS}$, many (20/30) relay cells fired at the pacemaker frequency with CVs ranging $16-70 \times 10^{-4}$ and a mean $\mathrm{CV}$ of $33 \times 10^{-4}$ (Fig. $8 \mathrm{~A}$ ). As the gap junction conductance increased, the minimum $\mathrm{CV}$ of all relay cells decreased, and the mean and range of the CVs also shifted to lower values (mean of $4.9 \times 10^{-4}$, range 3.6-6.9 $\times 10^{-4}$ at $g_{\text {gap }}=5 \mathrm{nS}$ ). The relay cell CVs were not further reduced with $g_{\text {gap }}$ values above $5 \mathrm{nS}$ due to the simulation time step, and therefore are not shown in the figure. The pacemaker cells in the same network with axosomatic coupling (not shown) had a minimum $\mathrm{CV}$ of $18 \times 10^{-4}$ (mean of $26 \times 10^{-4}$ ) at $1-\mathrm{nS}$ conductance. This minimum reduced only to $16 \times 10^{-4}$ (range $16-35 \times 10^{-4}$, mean of $26 \times 10^{-4}$ ) with a fivefold increase in conductance. There was no concurrent change in the firing frequency of the pacemaker or relay (Fig. 8B) cells. Giving pacemaker cells a distribution of intrinsic frequencies (with at least $10 \%$ variance in the current injected to set the cell frequency) did not change either cell type's response to increased gap junction conductance.

In a network with axoaxonic coupling and independent noise currents in each model cell as described above, all relay cells fired at the pacemaker frequency at a gap junction conductance as small as $1 \mathrm{nS}$. Again, increased $g_{\text {gap }}$ reduced the relay cell CVs (Fig. 8C) in their minimum (from $16 \times 10^{-4}$ to $4 \times 10^{-4}$ ) and mean from $28 \times 10^{-4}$ to $5 \times 10^{-4}$ ). Beyond $\sim 3 \mathrm{nS}$, the $\mathrm{CV}$ of relay cells no longer decreased, having reached the simulation's limit of resolution. The axoaxonic coupling among pacemaker cells only somewhat reduced their CV from a mean of $26 \times 10^{-4}$ to $22 \times 10^{-4}$ (Fig. $8 E$ ), such that the slope of $\mathrm{CV}$ against conductance was much lower than among the relay cells in this network. Increased $g_{\text {gap }}$ did increase the frequency of the relay cells (Fig. $8 D$ ), because of the pacemaker cells' increased frequency (Fig. $8 F$ ).

\section{Other effects of gap junction conductance}

The increased gap junction conductance, in both network configurations, had other effects as well. As mentioned above, the phase lag between model pacemaker and relay cells decreased with increasing gap junction conductance. In addition, the relative phase could shift between pairs of cells of the same type, even changing in sign. That is, one pacemaker cell could phase lag another at one value of $g_{\text {gap }}$, but phase lead it at another value. This type of shift in relative phase, with sign changes, was observed in the biological network (Moortgat et al. 2000). Gap junction conductance also modulated the apparent somatic spike amplitude. This effect was most pronounced in an electrically passive model relay soma.

\section{Network size: effects on CV}

To determine whether the network size affects the firing precision or frequency of noisy cells (noise as described above), we studied networks with different numbers of cells, always in a 4:1 ratio of pacemaker to relay cells that were coupled with the usual probabilities. Increasing the numbers of neurons while maintaining constant coupling probabilities results in each cell receiving a larger number of contacts on average, causing a greater gap junction drive. We normalized the gap junction conductance for the average number of con- 

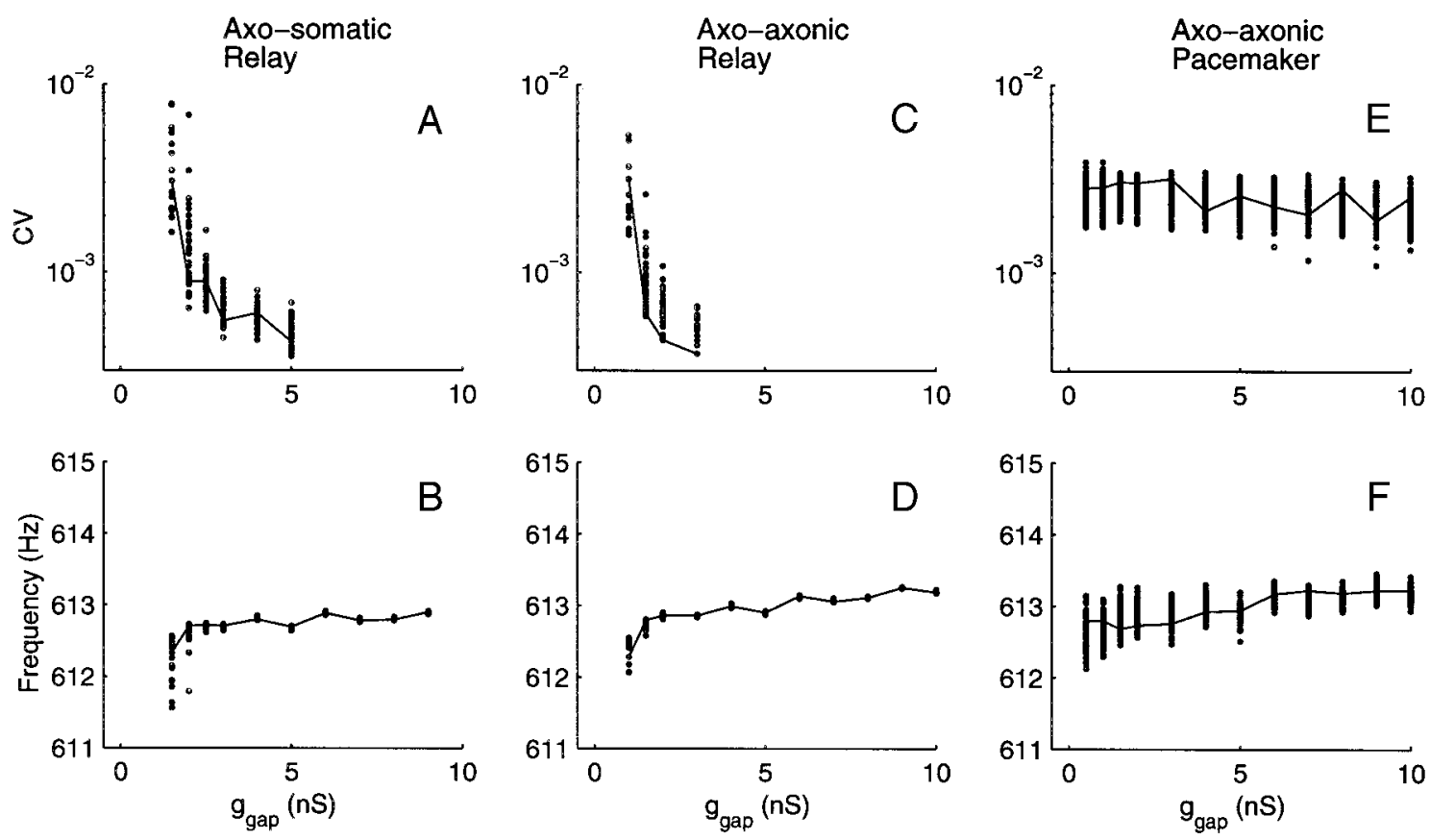

FIG. 8. Relay but not pacemaker cell CV decreases substantially with larger gap junction conductance. All cells in the network are injected with a noisy step current (mean $1.0 \mathrm{nA}, \mathrm{SD}=0.2 \mathrm{nA}$ ). Each dot represents a single cell in a network with coupling conductance given by the abscissa. A: relay cells in a network coupled by axosomatic gap junctions. As the gap junction conductance increased, the $\mathrm{CV}$ of the relay cell spike times decreased for an individual cell (-), and the mean and range of CVs for all cells decreased. The minimum $\mathrm{CV}$ was limited to $\sim 3 \times 10^{-4}$ by the time resolution of the simulation. $B$ : concurrently, the relay cells in the same network synchronized at the pacemaker cell intrinsic frequency $(612.5 \mathrm{~Hz}$, see Fig. 6). $C$ : relay cells in an axoaxonically coupled network reached the minimum CV at lower gap junction conductances than in the axosomatically coupled network. The decrease in CV and increase in frequency for the same representative relay cell as in $A$ and $B$ are indicated with the solid line. $D$ : the relay cells' increase in frequency is more pronounced in this network than shown in $(B) . E$ : pacemaker cells in the network coupled by axoaxonic gap junctions reduced their mean CV by only $30 \%$ (from a mean CV of 26 to $18 \times 10^{-4}$ ) over a 10-fold increase in gap junction conductance. The CV of one pacemaker cell (-) did not markedly decrease over the range of gap junction conductances. $F$ : pacemaker cells increased frequency with larger gap junction conductance, apparently driving the relay cells to increase frequency as well $(D)$.

tacts received by relay cells to maintain the same conductance and thus distinguish the effects of increased numbers of inputs from the effects of increased gap junction current drive (previous section).

The total number of cells in a network was varied from 50 to 200 , the approximate range observed in the biological pacemaker nucleus. Each cell in the model network was injected with an independent noisy current of $\mathrm{SD}=0.2 \mathrm{nA}$, and coupled with axoaxonic gap junctions of normalized conductance. The relay cells became more precise, with the average $\mathrm{CV}$ decreasing from $19 \times 10^{-4}$ to $5 \times 10^{-4}$ as the network grew from 50 to 200 cells (Fig. 9A). This CV decrease among relay cells was consistent with the law of large numbers (Helstrom 1991) for the number of contacts received. Namely, the $\mathrm{CV}$ decreases by $1 / \sqrt{N_{\mathrm{r}}}$, where $N_{\mathrm{r}}$ is the average number of contacts received by a relay cell. On the other hand, the pacemaker cells did not become more precise with increased numbers of cells in the network (Fig. 9C). Even taking into account the low probability of pacemaker-to-pacemaker cell contacts (0.07) compared with the probability of pacemakerto-relay cell contact $(0.35)$, and that the pacemaker cells therefore receive fewer contacts, the law of large numbers still predicted a larger $\mathrm{CV}$ decrease for pacemaker cells than the model demonstrated (Fig. 9C). Varying the network size from 50 to 200 cells did not impact the spiking frequency of either relay (Fig. 9B) or pacemaker cells (Fig. 9D), which remained fixed between 612.5 and $612.9 \mathrm{~Hz}$. This result reflects the successful normalization of $g_{\text {gap }}$ by the number of cells in the network. Networks made up of $<50$ neurons were not included in the figures because some cells received no contacts and did not spike.

The network size also failed to reduce pacemaker cell CV when cells were coupled with axosomatic gap junctions and when the SD of the injected noise was arbitrarily halved $(\mathrm{SD}=$ $0.1 \mathrm{nA}$ ). With axosomatic coupling, networks of all sizes had spiking frequencies of $\sim 612.7 \mathrm{~Hz}$, slightly lower than the 613 $\mathrm{Hz}$ seen with axoaxonic coupling. The relay cell $\mathrm{CV}$ decreased with the network size, but less so when cells were coupled axosomatically than when coupled axoaxonically.

\section{Contact probability: effects on $C V$ and frequency}

Although increasing the two global network parameters, the gap junction conductance $g_{\text {gap }}$, and the number of cells substantially reduced relay cell $\mathrm{CV}$, they failed to reduce the $\mathrm{CV}$ of pacemaker cells. To determine why the pacemaker cells were not changing $\mathrm{CV}$ while the relay cells did, we considered the differences between the two cell types. One difference is the number of contacts that cells of each type receive. To examine the possibility that low numbers of contacts would account for the limited decrease in pacemaker cell $\mathrm{CV}$, the probability of pacemaker cells contacting each other was in- 
creased by a factor of three and five times, such that each pacemaker cell received an average of 24 and 40 contacts, respectively. The $\mathrm{CV}$ was observed during increases in the gap junction conductance $g_{\text {gap }}$ in a network containing 150 neurons (120 pacemaker and 30 relay cells, each with the same mean current but independent noise of the same SD $=0.2 \mathrm{nA}$ ) that were coupled with axoaxonic gap junctions.

The relay cells' CVs reached the minimum resolvable value at $g_{\text {gap }}$ as low as $2 \mathrm{nS}$ in the network with five times the contact probability between pacemaker cells (Fig. 10A), a somewhat lower $g_{\text {gap }}$ than required in the network with normal contact probabilities (Fig. 8B). Also, the pacemaker cells' CVs decreased more with the higher contact probabilities (Fig. 10C) than with the normal probability of axoaxonic contacts (Fig. $8 E)$. That is, with five times the normal probability of axoaxonic contacts, the $\mathrm{CV}$ s of pacemaker cells decreased from a mean of $23 \times 10^{-4}$ to $15 \times 10^{-4}$ with a gap junction conductance increase from 1 to $10 \mathrm{nS}$, whereas with normal contact probability (see above) the mean pacemaker cell CV decreased from $26 \times 10^{-4}$ to $22 \times 10^{-4}$ over the same $g_{\text {gap }}$ change. For every conductance value, the $\mathrm{CV}$ was lower for higher contact probabilities, and the CV reduced more rapidly (higher slope with conductance).

Increasing contact probabilities affected network frequency more than did other parameters tested, raising it to $614.3 \mathrm{~Hz}$, just above the pacemaker cells' intrinsic frequency $(612.5 \mathrm{~Hz})$. Thus multiplying by five the probability of contacts between pacemaker cells reduced the $\mathrm{CV}$ of pacemaker cells by $<35 \%$
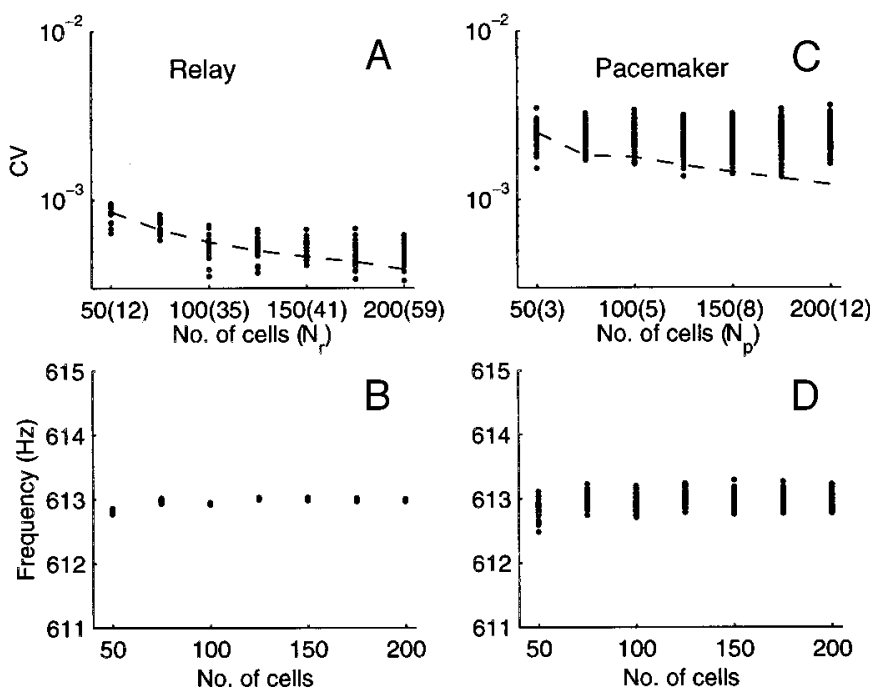

FIG. 9. CV of relay but not pacemaker cells decreases with the size of an axoaxonically coupled network. Each cell in the model network was injected with a Gaussian noise current of $\mathrm{SD}=0.2$ and is represented by a dot. $A$ : CVs of relay cells decreased with increasing number of cells in the network. The decrease roughly followed $1 / \sqrt{N_{\mathrm{r}}}$ (dashed line), where $N_{\mathrm{r}}$ is the average number of contacts received by relay cells and is labeled in parentheses for each abscissa value. $B$ : relay cell frequency remained relatively constant at 613 $\mathrm{Hz}$ over the tested range of network sizes. $C$ : in the same networks, the $\mathrm{CV}$ of pacemaker cells did not decrease with network size, not even at the moderate rate of $1 / \sqrt{N_{\mathrm{p}}}$ (dashed line), where $N_{\mathrm{p}}$ is the average number of contacts received by pacemaker cells and is labeled in parentheses for each abscissa value. $D$ : pacemaker cell frequency was also not affected by the increased network size. The gap junction conductance is normalized for the number of contacts received, starting with a conductance of $5 \mathrm{nS}$ for a network of 150 cells.
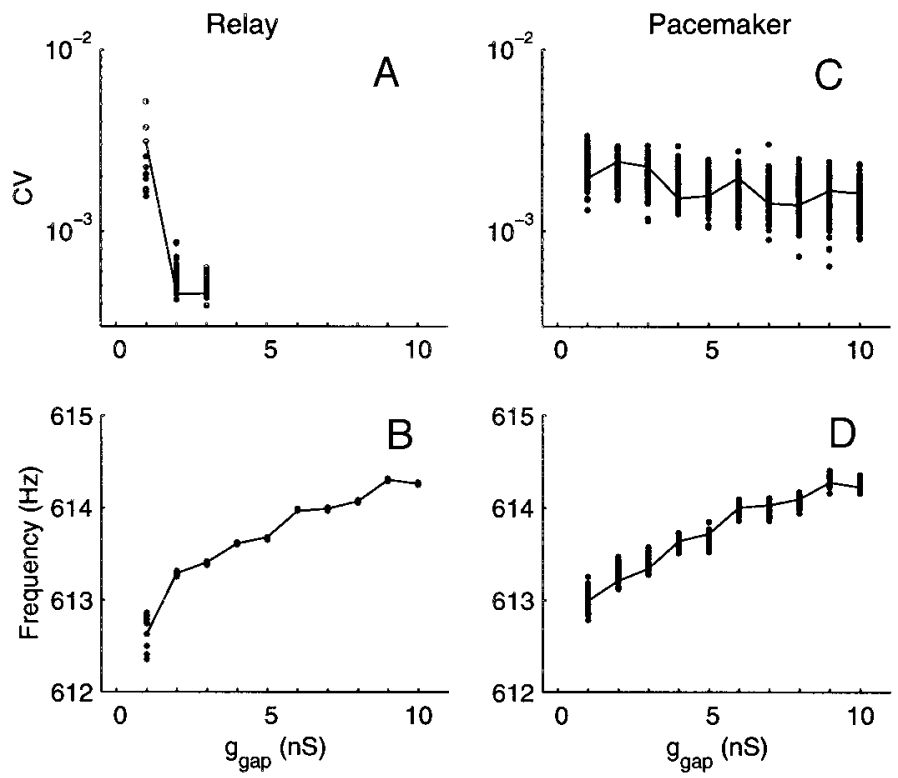

FIG. 10. In a network with 5 times the usual probability of axoaxonic contacts between pacemaker cells, both cell types decrease CV and increase frequency with larger gap junction conductance. The same noisy current was injected into these cells as in Figs. 8 and 9. A: CVs of relay cells (one relay cell, solid line) dropped rapidly from $\sim 20-30 \times 10^{-4}$ (mean of $28 \times 10^{-4}$ ) to $3.9-6.3 \times 10^{-4}$ (mean of $\left.5.1 \times 10^{-4}\right)$. $B$ : relay cell frequency increased by a mean of $1.6 \mathrm{~Hz}$ over a 10-fold increase in gap junction conductance. $C$ : the $\mathrm{CV}$ of pacemaker cells (one pacemaker cell, solid line) decreased from an average of 23 to $15 \times 10^{-4}$. D: the pacemaker cells' frequency increased with gap junction conductance.

and allowed a 2-Hz increase of the network frequency above the intrinsic pacemaker frequency.

A network with high probabilities of axosomatic (rather than axoaxonic) contacts was also studied. The results were similar in both networks, although the effects on CV and frequency were less pronounced in the axosomatic network than even the moderate effects in the network with axoaxonic gap junctions. This was part of the general trend that networks with axoaxonic gap junctions have larger changes in CV and even frequency than seen in networks with axosomatic gap junctions.

\section{Other network parameters have only limited effects on pacemaker cell $\mathrm{CV}$ and frequency}

We sought other network parameters that would modulate the CV of pacemaker cells when they were coupled in a network. The primary remaining parameters that differ between pacemaker and relay cells are the high axial resistance $R_{\mathrm{a}}$ of the relay cell axon, and the passive membrane in the relay cell soma. Raising the $R_{\mathrm{a}}$ of the pacemaker cell axon did not help reduce the pacemaker cell CVs; and adding active conductances to the relay cells did not remove their ability to reduce $\mathrm{CV}$ with increasing gap junction conductance.

\section{I S C U S S I O N}

Until now, no proposed mechanism has adequately explained the phenomenal precision of the weakly electric fish's Pn neurons, although the question and its significance have been recognized for three decades. We propose an explanation, based primarily on the above network model and in vitro physiology, in two steps. First, the pacemaker cells are intrin- 
sically more precise (lower CV) than any previously known cellular biological clock. Second, these cells converge on relay cells with a ratio of $\sim 40: 1$ and a conductance of $4 \mathrm{nS}$, which together reduce the relay cell $\mathrm{CV}$ by an average of $\sim 10$ times. Several possible mechanisms are suggested that could be under central control and explain the biologically observed modulations of regularity.

With a simple network model, we explored the genesis of the high precision of the weakly electric fish's pacemaker nucleus and the biologically observed responses of neurons in this nucleus to current injection. The model was composed of 150 2-compartment neurons of 2 types, containing sodium and potassium Hodgkin-Huxley-type currents, and coupled with gap junctions. The model reproduced many detailed physiological results and made new predictions for the electric fish's pacemaker nucleus, in particular, and for gap junction-coupled oscillators in general. Also, the model predicted that not only networks of neurons, but single neurons themselves are capable of the extreme precision $\left(\mathrm{CV}=6-25 \times 10^{-4}\right)$ observed in the biological Pn.

Biologically reasonable values of cellular parameters gave the observed low input resistance for both cell types, and, for pacemaker cells, a high intrinsic spiking frequency and the ability to drive other cells to fire. We included only sodium and potassium currents, although we know that calcium also plays an important role in setting the firing frequency (Dye 1991), possibly producing a pacemaker potential in a role similar to that in many other pacemaker cells (Hille 1992). Here, the role of the pacemaker potential was played by a continuous step current. The injected currents and their distribution on the cell membrane produced spikes that had similar waveform and relative amplitude to those seen in the biological homologue. The absolute amplitudes, however, are significantly larger in the model than in the biological neurons, probably because of differences in the recording location. The relative amplitude decay between the somatic and axonic compartments of a relay cell was largely determined by the passive relay soma, and the high axial resistance of the relay axon, as suggested for dendrites of neocortical pyramidal neurons (Mainen and Sejnowski 1996).

Model pacemaker cells were coupled to each other, and model pacemaker cells were coupled to model relay cells roughly according to the statistics of anatomic data (Dye and Heiligenberg 1987; Moortgat et al. 2000), with a maximum of one gap junction per cell pair. Interrelay cell coupling was not incorporated in the model despite anatomic evidence of dendrosomatic gap junctions among relay cells (Moortgat et al. 2000) for two reasons. First, the model did not include dendritic compartments. Second, the effect on the network frequency and precision due to distant gap junctions on fine processes would be minimal. The dendritic gap junctions may be more involved during modulations of network frequency that are driven by higher brain centers by way of the relay cell dendrites (Heiligenberg et al. 1996; Spiro 1997).

Simulations began with all cells arbitrarily at the same phase (zero phase lag), but the phase rapidly changed to new stable values, and many cells simultaneously received increased gap junctional currents. The increased input arose from increased phase lags among cells. That is, a gap junction only passes current when the voltage across it is nonzero; in the case of coupled oscillators, the phase between cells must be nonzero.
At the same time, an overly broad phase distribution may not drive the contacted relay cells above spike threshold. The network might effectively be maximizing, over the first oscillation cycles, the total current passed through all the gap junctions or some other function of phase lag.

The final distribution of phases depended on the gap junction conductance, which was chosen to be 5 and $4 \mathrm{nS}$, respectively, in networks with axosomatic and axoaxonic coupling, to fit the biologically observed $10-15 \%$ phase lags between pacemaker and relay cells (Dye 1988; Moortgat et al. 2000). The factor of 4 or 5 higher conductance than, for example, the $1 \mathrm{nS}$ directly measured between rat cardiac cells (Spray et al. 1985), could result from larger numbers of gap junction channels, even at a single club ending, as well as higher unitary conductance (conductance per gap junction channel). Unitary conductances are connexin-specific and range as widely as $30-300 \mathrm{pS}$ in mammals (Spray 1997). Thus the model predicts a biologically plausible gap junction conductance.

Phase lags not only between but also within cell types shifted with gap junction conductance. Also, the phase lag between any cell pair varied with gap junction conductance: a cell that spiked after its neighbor at one conductance could spike ahead of it at another conductance. Such phase shifts were observed in vitro when gap junction blockers (aimed at reducing the gap junction conductance) were applied (see Fig. $7 B 1$ of Moortgat et al. 2000). Thus the in vitro result is consistent with blockage of gap junctions. A cell's phase also depended on injected current, both in this model and in the biological preparation. Because the model used injected current to set a cell's intrinsic firing frequency, shifting the injected current effectively changed its intrinsic firing frequency. Thus another explanation for the relative phase shifts seen when gap junction blockers were applied to biological cells is that cells changed relative to one another in intrinsic frequency. This could occur if the gap junction blocker altered the intrinsic frequencies of cells in some spatially dependent way: for example, different network locations could have received different blocker concentrations. However, other lines of evidence (frequency change, below) support the conclusion that gap junction conductances were indeed decreasing with drug application.

Current injections to model neurons qualitatively replicated the sometimes perplexing in vitro results. Namely, the currents never altered the frequency of membrane voltage oscillations. Also, the responses to moderate and large hyperpolarizing currents ( 0 to $-10 \mathrm{nA})$ had only limited effects on the spike amplitude while substantially driving the peak spike voltage. A narrow range of hyperpolarizing currents led a biological or model neuron in a network to alternate between high and low oscillation amplitudes. The range of currents required for this alternation pattern were quantitatively similar in the biological and model cells. In the model cells, we could attribute variation in the required current to the number and location of gap junction contacts that the cell received, with larger currents required for high conductance gap junction inputs located at axons (axoaxonic coupling). Even the details of the minimum voltage achieved after high- and low-amplitude oscillations were reproduced in the model (Fig. 6, $A$ and $B$ ). That these experimental results were reproduced, without additional model parameter tuning, supports the validity of our model.

Simulations revealed that the high-amplitude oscillations 
reflected full spikes, whereas the low-amplitude oscillations are the passive response to gap junction input. We could not test this possibility in the biological cells, but we confirmed it in selected model pacemaker and relay cells by removing all active conductances in those cells and observing the same low-amplitude oscillations. The model showed that a narrow range of somatic currents produced the biologically observed spike skipping in a 1:2 ratio with cycles of the network, and predicted that further hyperpolarizing a Pn neuron should stop its active spiking altogether. The model also predicted that other ratios of skipped spikes to network oscillations, including $1: 3,1: 4$, and 1:5, could occur in relay cells and that spikes would have graded amplitude. Neither the graded amplitudes nor the low ratios were observed in the biological relay cells (Moortgat et al. 2000), perhaps because of the narrow range of currents that produce them. The biological pacemaker cells did show the low ratios, without graded spike amplitudes.

To study the effects of gap junctions on spiking precision, we included a stochastic process in our deterministic model. Biological sources of noise are typically differentiated between external synaptic noise, and intrinsic noise of the spike initiation mechanism that includes cellular morphology as well as ion channel fluctuations. The intrinsic noise is thought to be dominated by the latter. Models have incorporated noise in many ways: from a fluctuating spike threshold in an integrate and fire model (Reich et al. 1997) to ion channel-specific fluctuations (Wilders and Jongsma 1993) in a modified Hodgkin-Huxley model.

We added intrinsic noise in another way, through a timevarying current injection into each cell's soma. In networks of cells that each received independent noise current, cells had intrinsic variability in their spikes times of $\mathrm{CV}=30 \times 10^{-4}$. We tested whether gap junctions among pacemaker cells and between pacemaker and relay cells could reduce the CV of spiking, as has been reported for coupled photoreceptors, for example (Lamb and Simon 1976). Coupling the noisy Pn neurons with gap junctions, and increasing the gap junction conductance from 0 to $4-5 \mathrm{nS}$ caused rapid and dramatic reductions of the $\mathrm{CV}$ of relay cell spike times, without significantly altering the pacemaker cell CVs. Thus the model suggests that coupling Pn cells with gap junctions of biologically plausible conductance can reduce relay cell $\mathrm{CV}$ from $\sim 30 \times$ $10^{-4}$ by a factor of $\sim 10$. This may be part of the explanation for the low CV observed in relay cells. Also, behavioral modulations in the CV (Moortgat et al. 1998) could be achieved by changing gap junction conductance. Relevant sensitivities of gap junction conductance include $\mathrm{pH}$, voltage, and calcium concentrations (Spray and Bennett 1985). Calcium concentrations in particular could be adjusted in the vicinity of gap junctions by co-localized glutamate receptors, known to be involved in the modulation of Pn frequency (Heiligenberg et al. 1996; Kawasaki and Heiligenberg 1989; Keller et al. 1991) and possibly involved in CV modulation (Moortgat et al. 1998). Alternatively, active glutamate receptors may directly increase the CV by opening synaptic current channels that would normally be closed. As mentioned above, synaptic currents have long been thought to cause high CVs in some neurons.

We observed a frequency increase with increasing gap junction conductance in both the model, and, we believe, in vitro. These results are qualitatively consistent with other models of gap junction-coupled oscillators that show that increased gap junction conductance can change pacemaking frequency in a direction that depends on spike shape (Chow and Kopell 1999; Kepler et al. 1990). However, our results are quantitatively most plausible for the Pn. Specifically, Kepler et al.'s model used gap junction conductances that were a factor of 1,000 higher than the range we considered for Pn coupling. Within the range of conductances we tested, the frequency of model cells changed by $<1 \%$, well below the experimentally observed 30-50\% decrease when pharmacological gap junction blockers were applied (Moortgat et al. 2000). On the other hand, other model neurons (Chow and Kopell 1999) showed a fivefold decrease in frequency with a fivefold reduction in gap junction conductance. We conclude that the effect on frequency by the gap junction blockers was partially due to blocking gap junctions, but was also influenced by drug side effects. For example, the drugs may have reduced calcium and sodium conductances and thereby substantially reduced the pacemaking frequency.

Distributing pacemaker cell intrinsic frequencies ( $I_{\text {inj: }}$ : mean $=1.0 \mathrm{nA}, \mathrm{SD}=0.2$ ), did not obviously alter the frequency locking or $\mathrm{CV}$ of coupled model neurons within the tested range of gap junction conductances. However, substantially different choices of frequency distribution and coupling strength (possibly outside the biological range) might lead to significantly different spiking patterns, as described in oscillators with mean-field coupling (Matthews and Strogatz 1990).

Adding cells to a network while normalizing the gap junction conductance to the average number of contacts received by relay cells also reduced only the relay cell $\mathrm{CV}$, but only moderately (by $\sim 1 / \sqrt{N_{\mathrm{r}}}$, where $N_{\mathrm{r}}$ is the average number of contacts received by each relay cell). The CVs of pacemaker cells were not changed between the same 50 to 200-cell networks. This result is consistent with the biological observation that increasing the numbers of neurons beyond $\sim 50$ in the Pn of one species of weakly electric fish does not significantly reduce the CV of pacemaking (Hagedorn et al. 1992).

For the Pn to send a precisely timed drive to the fish's output tail organ (the electric organ) only the Pn's relay cells need to have particularly low CV. However, we only observe CVs in the range of 6 to $30 \times 10^{-4}$ in the biological Pn, with most cells within 10 to $20 \times 10^{-4}$. There was no evidence for the bimodal distribution suggested by the model. The only network parameter that decreased pacemaker cell CV below its intrinsic values (set by the noise current to $30 \times 10^{-4}$ ) was an increased probability of contact between pacemaker cells. Increasing the probability to three to five times the numbers in the anatomic data slightly reduced the CV of pacemaker cells.

What is the intrinsic CV of single, isolated pacemaker and relay cells? This has not yet been directly measured in vitro. All simulations assumed that the CV of model pacemaker cells is $30 \times 10^{-4}$ (Fig. 8-10) or lower (not shown). However, most reports of cellular precision (weakly electric fish's pacemakers and circadian rhythms are notable exceptions) describe CVs of 0.01-0.1 at a minimum. If model pacemaker cells had intrinsic CVs of this value, then our model predicts we would have measured biological CVs of this same order. However, CVs in isolated or in vivo nuclei were below $\sim 25 \times 10^{-4}$, with a few minor exceptions that could reflect poor intracellular recordings. Our model predicts that, unless the reported anatomy of pacemaker to pacemaker contacts is wrong by a factor of five 
or more, the observed biological CVs will only occur when individual pacemaker cells have low intrinsic CVs.

We therefore conclude that biological pacemaker cells have an intrinsically low CV; at least as low as 20 to $25 \times 10^{-4}$, which is at the high end of the CVs observed in the biological Pn, but well below the CV of any other known biological system. The biological relay cells may have slightly lower CVs than pacemaker cells, with the lowest CVs primarily in cells with more independent gap junction contacts, and secondarily in those with more axoaxonic compared with axosomatic contacts.

Further research will be required to determine whether these neurons are "normal," with high precision that is in fact possible in many neural systems but that has not yet been seen because of more complicated synaptic circuitry. Alternatively, the individual Pn neurons may be specialized for high precision firing. One specialization that appears to improve fidelity in photoreceptors is having a high density of ion channels whose $25 \mathrm{pA}$ conductances are blocked to $4 \mathrm{fA}$ (for review see Yau and Baylor 1989). The partial block reduces the noise from each ion channel, whereas the high channel density allows enough current to enter the cells. Similar investigation of the Pn cells and their ion channels will require new experiments and techniques.

The correspondence between the experimental results for current injection and gap junction blockade and the model reported here is surprisingly good, given the simplicity of the model. Only two currents were included in the model and their kinetics were not constrained by detailed biophysical channel measurements, which have not been performed. This suggests that the qualitative and some quantitative (e.g., the range of hyperpolarizing current that is required for a neuron to skip spikes) properties of the model are dependent primarily on the connectivity and passive properties of the neurons and do not depend on the details of the channel kinetics.

We thank J. Enright, J. M. Fellous, and R. Traub for helpful discussions; J. M. Fellous, Z. Mainen, W. Wheeler, and M. Hines for assistance with NEURON; and W. Kristan and two anonymous reviewers for insightful critique of the manuscript.

K. T. Moortgat was supported by National Institute of Mental Health Predoctoral Fellowship MH-10864-03 and by the Sloan Foundation; T. H. Bullock by the National Institute of Neurological Disorders and Stroke; and T. J. Sejnowski by the Howard Hughes Medical Institute.

Present address and address for reprint requests: K. T. Moortgat, Sloan Center, Dept. of Physiology, University of California, San Francisco, Box 0444, 513 Parnassus Ave., San Francisco, CA 94143-0444.

Received 19 March 1999; accepted in final form 18 October 1999.

\section{REFERENCES}

Bullock, T. H. The reliability of neurons. J. Gen. Physiol. 55: 565-584, 1970.

Bullock, T. H., Hamstra, R. H., And Scheich, H. The jamming avoidance response of high frequency electric fish. I and II. J. Comp. Physiol. 77: $1-48,1972$.

Carr, C. E., Heiligenberg, W., and Rose, G. J. A time-comparison circuit in the electric fish midbrain. I. Behavior and physiology. J. Neurosci. 6: 107-119, 1986.

Chow, C. C. AND Kopell, N. Dynamics of spiking neurons with electrical coupling. Neural Comp. In press.

DYE, J. Dynamics and stimulus-dependence of pacemaker control during behavioral modulations in the weakly electric fish Apteronotus. J. Comp. Physiol. [A] 161: 175-185, 1987.
DYE, J. An in vitro physiological preparation of a vertebrate communicatory behavior: chirping in the weakly electric fish Apteronotus. J. Comp. Physiol. [A] 163: 445-458, 1988.

DYE, J. Ionic and synaptic mechanisms underlying a brainstem oscillator: an in vitro study of the pacemaker nucleus of Apteronotus. J. Comp. Physiol. [A] 168: 521-532, 1991.

DYe, J. AND HeILIGENBERG, W. Intracellular recording in the medullary pacemaker nucleus of the weakly electric fish Apteronotus, during modulatory behaviors. J. Comp. Physiol. [A] 161: 187-200, 1987.

EleKes, K. AND SzABo, T. Synaptology of the medullary command (pacemaker) nucleus of the weakly electric fish (Apteronotus leptorhynchus) with particular reference to comparative aspects. Exp. Brain Res. 60: 509-520, 1985.

EnRIGHT, J. T. Temporal precision in circadian systems: a reliable neuronal clock from unreliable components? Science 209: 1542-1545, 1980a.

EnRIGHT, J. T. The Timing of Sleeping and Wakefulness. New York: SpringerVerlag, 1980b.

Ernst, U., PawelziK, K., and Geisel, T. Synchronization induced by temporal delays in pulse-coupled oscillators. Physiol. Rev. Lett. 74: 1570-1573, 1995.

Hagedorn, M. and Heiligenberg, W. Court and spark: electric signals in the courtship and mating of gymnotoid fish. Anim. Behav. 33: 254-265, 1985.

Hagedorn, M., Vischer, H. A., AND HeILIGENBERG, W. Development of the jamming avoidance response and its morphological correlates in the gymnotiform electric fish Eigenmannia. J. Neurobiol. 23: 1446-1466, 1992.

Hansel, D., Mato, G., And Meunier, C. Synchrony in excitatory neural networks. Neural Comp. 7: 307-337, 1995.

HeILIGENBERG, W. Neural Nets in Electric Fish. Cambridge, MA: MIT Press, 1991.

Heiligenberg, W., Finger, T., Matsubara, J., and Carr, C. Input to the medullary pacemaker nucleus in the weakly electric fish Eigenmannia (sternopygidae, gymnotiformes). Brain Res. 211: 418-423, 1981.

Heiligenberg, W., Metzner, W., Wong, C. J., and Keller, C. H. Motor control of the jamming avoidance response of Apteronotus leptorhynchus: evolutionary changes of a behavior and its neuronal substrates. J. Comp. Physiol. [A] 179: 653-674, 1996.

Helstrom, C. Probability and Stochastic Processes for Engineers (2nd ed.). New York: Macmillan, 1991.

HiLLE, B. Ionic Channels of Excitable Membranes (2nd ed.). Sunderland, MA: Sinauer, 1992.

HiNES, M. Neuron-a program for simulation of nerve equations. In: Neural Systems: Analysis and Modeling, edited by F. H. Eeckman. Norwell, MA: Kluwer Academic Publishers, 1993, p. 127-136.

Hodgkin, A. L. AND HuXley, A. F. A quantitative description of membrane current and its application to conduction and excitation in nerve. J. Physiol. (Lond.) 117: 500-544, 1952

JURANEK, J. AND METZNER, W. Segregation of behavior-specific synaptic inputs to a vertebrate neuronal oscillator. J. Neurosci. 18: 9010-9019, 1998.

KaWASAKI, M. AND HeIligenberg, W. Distinct mechanisms of modulation in a neuronal oscillator generate different social signals in the electric fish Hypopomus. J. Comp. Physiol. [A] 165: 731-741, 1989.

Keller, C., Kawasaki, M., and Heiligenberg, W. The control of pacemaker modulations for social communication in the weakly electric fish Sternopygus. J. Comp. Physiol. [A] 169: 441-450, 1991.

Kepler, T. B., Marder, E., AND Aвbott, L. F. The effect of electrical coupling on the frequency of model neuronal oscillators. Science 248: $83-85,1990$.

LAMB, T. D. AND Simon, E. J. The relation between intercellular coupling and electrical noise in turtle photoreceptors. J. Physiol. (Lond.) 263: 257-286, 1976.

MAINEN, Z. F. AND SEJNOwSKI, T. J. Influence of dendritic structure on firing pattern in model neocortical neurons. Nature 382: 363-366, 1996.

Matthews, P. C. and Strogatz, S. H. Phase diagram for the collective behavior of limit-cycle oscillators. Physiol. Rev. Lett. 65: 1701-1704, 1990.

MEYER, J. Steroid influences upon discharge frequencies of intact and isolated pacemakers of weakly electric fish. J. Comp. Physiol. [A] 154: 659-668, 1984.

Moortgat, K. T. Precision of Pacemaking in a Weakly Electric Fish: Behavior, Physiology, and Modeling ( $\mathrm{PhD}$ thesis). San Diego, CA: Univ. of California, 1999. 
Moortgat, K. T., Bullock, T. H., And Sejnowski, T. J. Precision of the pacemaker nucleus in a weakly electric fish: network versus cellular influences. J. Neurophysiol. 83: 971-983, 2000.

Moortgat, K. T., Keller, C., Bullock, T., and Sejnowski, T. Submicrosecond pacemaker precision is behaviorally modulated: the gymnotiform electromotor pathway. Proc. Natl. Acad. Sci. USA 95: 4684-4689, 1998.

Reich, D. S., Victor, J. D., Knight, B. W., Ozaki, T., and Kaplan, E. Response variability and timing precision of neuronal spike trains in vivo. J. Neurophysiol. 77: 2836-2841, 1997.

SHERMAN, A. AND RinZEL, J. Model for synchronization of pancreatic $\beta$-cells by gap junction coupling. Biophys. J. 59: 547-559, 1991.

ShinBRot, T. AND SCARBROUGH, K. Using variability to regulate long term biological rhythms. J. Theor. Biol. 196: 455-471, 1999.

SPIRO, J. E. Differential activation of glutamate receptor subtypes on a single class of cells enables a neural oscillator to produce distinct behaviors. J. Neurophysiol. 78: 835-847, 1997.
SPRAY, D. C. Physiological properties of gap junction channels in the nervous system. In: Gap Junctions in the Nervous System, edited by D. C. Spray and R. Dermietzel. R. G. Austin, TX: Landes, 1997, p. 39-59.

SpRAy, D. C. AND BennetT, M. V. Physiology and pharmacology of gap junctions. Annu. Rev. Physiol. 47: 281-303, 1985.

Spray, D. C., White, R. L., Mazet, F., And Bennett, M. V. Regulation of gap junctional conductance. Am. J. Physiol. 248 (Heart Circ. Physiol. 17): H753-H764, 1985.

von der Emde, G., Schwarz, S., Gomez, L., Budelli, R., and Grant, K. Electric fish measure distance in the dark. Nature 395: 890-894, 1998.

WILDERS, R. AND JONGSMA, H. J. Beating irregularity of single pacemaker cells isolated from the rabbit sinoatrial node. Biophys. J. 65: 2601-2613, 1993.

YAU, K. W. AND BAYlor, D. A. Cyclic gmp-activated conductance of retinal photoreceptor cells. Annu. Rev. Neurosci. 12: 289-327, 1989. 